\title{
Parameter Study of Melt Spun Polypropylene Fibers by Centrifugal Spinning
}

\author{
by Daniel M Sweetser and Nicole E Zander
}




\section{NOTICES}

\section{Disclaimers}

The findings in this report are not to be construed as an official Department of the Army position unless so designated by other authorized documents.

Citation of manufacturer's or trade names does not constitute an official endorsement or approval of the use thereof.

Destroy this report when it is no longer needed. Do not return it to the originator. 


\title{
Army Research Laboratory
}

Aberdeen Proving Ground, MD 21005-5066

ARL-TN-0619

July 2014

\section{Parameter Study of Melt Spun Polypropylene Fibers by Centrifugal Spinning}

\author{
Daniel M Sweetser and Nicole E Zander \\ Weapons and Materials Research Directorate, ARL
}




\section{REPORT DOCUMENTATION PAGE}

Public reporting burden for this collection of information is estimated to average 1 hour per response, including the time for reviewing instructions, searching existing data sources, gathering and maintaining the data needed, and completing and reviewing the collection information. Send comments regarding this burden estimate or any other aspect of this collection of information, including suggestions for reducing the burden, to Department of Defense, Washington Headquarters Services, Directorate for Information Operations and Reports (0704-0188), 1215 Jefferson Davis Highway, Suite 1204, Arlington, VA 22202-4302. Respondents should be aware that notwithstanding any other provision of law, no person shall be subject to any penalty for failing to comply with a collection of information if it does not display a currently valid OMB control number.

PLEASE DO NOT RETURN YOUR FORM TO THE ABOVE ADDRESS.

\begin{tabular}{|l|l|l}
\hline 1. REPORT DATE (DD-MM-YYYY) & 2. REPORT TYPE & 3. DATES COVERED (From - To) \\
July 2014 & Final & October 2013-June 2014
\end{tabular}

4. TITLE AND SUBTITLE

October 2013-June 2014

Parameter Study of Melt Spun Polypropylene Fibers by Centrifugal Spinning 5a. CONTRACT NUMBER

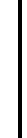

6. AUTHOR(S)

Daniel M Sweetser and Nicole E Zander

\begin{tabular}{|c|c|}
\hline \multirow[t]{2}{*}{ cos } & 5e. TASK NUMBER \\
\hline & 5f. WORK UNIT NUMBER \\
\hline 9. SPONSORING/MONITORING AGENCY NAME(S) AND ADDRESS(ES) & $\begin{array}{l}\text { 11. SPONSOR/MONITOR'S REPORT } \\
\text { NUMBER(S) }\end{array}$ \\
\hline
\end{tabular}

\section{DISTRIBUTION/AVAILABILITY STATEMENT}

Approved for public release; distribution is unlimited.

\section{SUPPLEMENTARY NOTES}

\section{ABSTRACT}

Nanofibers and microfibers offer a myriad of applications ranging from filtration, composites, and energy harvesting to tissue engineering and drug delivery. Centrifugal spinning is a new technique that uses centrifugal forces to form nanofibers and microfibers both from solution and the melt. In this work, polypropylene fibers were prepared using centrifugal spinning from the melt. The effects of melt temperature, spinneret orifice diameter, collector distance, and rotation speed were evaluated with respect to fiber morphology and diameter. The optimal heating temperature was found to be between 200 and $230{ }^{\circ} \mathrm{C}$ to produce bead-free fibers. Decreasing the spinneret orifice diameter and increasing the rotation speed of the spinneret yielded more uniform fibers with smaller diameters.

\section{SUBJECT TERMS}

centrifugal spinning, polypropylene, nanofibers, melt spinning, electron microscopy

\begin{tabular}{|l|l|l|c|c|l|}
\hline \multicolumn{2}{|l|}{ 16. SECURITY CLASSIFICATION OF: } & $\begin{array}{l}\text { 17. LIMITATION } \\
\text { OF ABSTRACT }\end{array}$ & $\begin{array}{l}\text { 18. NUMBER } \\
\text { OF PAGES }\end{array}$ & $\begin{array}{l}\text { 19a. NAME OF RESPONSIBLE PERSON } \\
\text { Nicole Zander }\end{array}$ \\
\cline { 1 - 2 } $\begin{array}{l}\text { a. REPORT } \\
\text { Unclassified }\end{array}$ & $\begin{array}{l}\text { b. ABSTRACT } \\
\text { Unclassified }\end{array}$ & $\begin{array}{l}\text { c. THIS PAGE } \\
\text { Unclassified }\end{array}$ & UU & 16 & $\begin{array}{l}\text { 19b. TELEPHONE NUMBER (Include area code) } \\
410-306-1965\end{array}$ \\
\hline
\end{tabular}




\section{Contents}

List of Figures $\quad$ iv

List of Tables $\quad$ iv

$\begin{array}{ll}\text { 1. Introduction } & 1\end{array}$

2. Materials and Methods 1

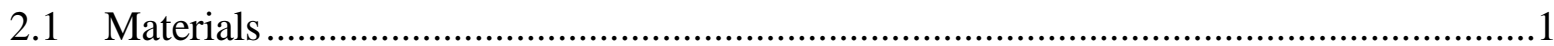

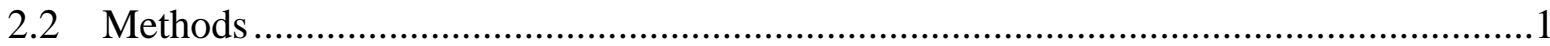

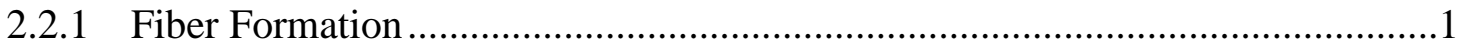

2.2.2 Fiber Characterization .........................................................................2

3. Results and Discussion $\quad 2$

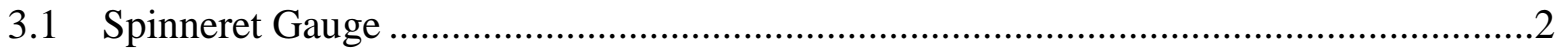

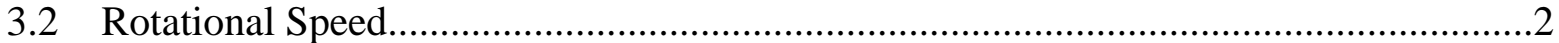

3.3 Temperature

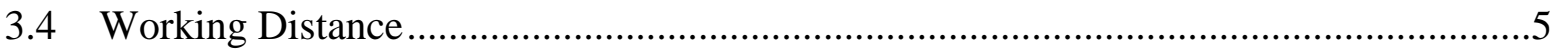

$\begin{array}{ll}\text { 4. Conclusions } & 7\end{array}$

$\begin{array}{llr}\text { 5. } & \text { References } & 8\end{array}$

$\begin{array}{ll}\text { Distribution List } & 9\end{array}$ 


\section{List of Figures}

Fig. 1 SEM images paired with fiber diameter distributions of PP microfibers melt spun with a 30-G spinneret at $230^{\circ} \mathrm{C}$ and a collector distance of $14 \mathrm{~cm}$ with varying rotational speeds. a/b) 6,000 rpm, c/d) 10,000 rpm, e/f) 14,000 rpm, and g/h) 18,000 rpm

Fig. 2 Melt spun polypropylene fiber diameters prepared at $230{ }^{\circ} \mathrm{C}$ and at a working distance of $14 \mathrm{~cm}$

Fig. 3 SEM micrographs of polypropylene fibers produced at 14,000 rpm, with a working distance of $14 \mathrm{~cm}$ at varying temperatures: a) $200{ }^{\circ} \mathrm{C}$, b) $230{ }^{\circ} \mathrm{C}$, and c) $250{ }^{\circ} \mathrm{C}$ .5

Fig. 4 SEM images of polypropylene fibers produced at $230{ }^{\circ} \mathrm{C}, 14,000 \mathrm{rpm}$, and varying spinneret-collector distances: a) $10 \mathrm{~cm}$, b) $12 \mathrm{~cm}$, and c) $14 \mathrm{~cm}$

Fig. 4 SEM images of polypropylene fibers produced at $230{ }^{\circ} \mathrm{C}, 14,000 \mathrm{rpm}$, and varying spinneret-collector distance. a) $10 \mathrm{~cm}$, b) $12 \mathrm{~cm}$, and c) $14 \mathrm{~cm}$

Fig. 5 Normalized distributions of fiber diameters produced at $230{ }^{\circ} \mathrm{C}, 14,000 \mathrm{rpm}$, and varying spinneret-collector distances

\section{List of Tables}

Table 1 Fiber diameter of melt-spun polypropylene fibers at varying rotational speeds .4

Table 2 Fiber diameter averages and standard deviations at different operating temperatures .....5

Table 3 Fiber diameter averages and standard deviations with distribution peak heights at different working distances. 


\section{Introduction}

The production of microfibers and nanofibers has drawn an increasing amount of attention during the last decade. The interest for nanofibers is rooted in the unique properties they contain such as their high surface area to volume ratios. These unique properties lead to many applications in areas such as energy, filtration, drug delivery, and tissue repair. ${ }^{1-3}$ There are many methods of fabricating nanofibers including drawing, template synthesis, phase separation, selfassembly, and electrospinning. Most methods are only relevant on a laboratory scale and are not economically feasible enough to be scaled up to industry. Recently, nanofiber production via centrifugal spinning has received more attention as an alternative to electrospinning, the most common nanofiber formation method. Fibers of low dielectric constants and insoluble polymers that generally cannot be used in electrospinning can be produced through centrifugal spinning. The centrifugal spinning process has several key parameters that control fiber morphology (in addition to solution viscosity) including the rotational speed of the spinneret, working distance between spinneret and collector, and heating temperature. ${ }^{4}$ In this work, we examined the effect of the aforementioned parameters on polypropylene fiber formation.

\section{Materials and Methods}

\subsection{Materials}

Polypropylene (PP) was provided by FibeRio (FibeRio Technology Corp.) and used as received.

\subsection{Methods}

\subsubsection{Fiber Formation}

Melt spun fibers were fabricated using the FiberLab L1000-D (Fiberio Technology Corp.). Polypropylene (PP) pellets (200 mg) were added to the $30-\mathrm{G}$ and $20-\mathrm{G}$ spinnerets purchased from Fiberio. The PP polymer was heated to temperatures ranging from 200 to $250{ }^{\circ} \mathrm{C}$. Polymer temperature was measured with a thermocouple inserted into the spinneret. The spinneret was spun for $30 \mathrm{~s}$ at a rotational speed of 6,000-18,000 rpm. The 6-inch-high,

1/2-inch-wide collector bars were separated by 1 inch and arranged in a circle surrounding the spinneret. Collector bars were placed 10,12, and $14 \mathrm{~cm}$ away from the spinneret orifices. Aluminum foil covered selected bars and was used to collect the melt spun PP fibers. 


\subsubsection{Fiber Characterization}

Fiber morphology was observed using a field emission scanning electron microscope (SEM, Hitachi S-4700). The fiber webs were gold/palladium sputtered to reduce charging. Fibers from these images were selected at random to measure fiber diameter, performed with Image $\mathbf{J}$ software.

\section{Results and Discussion}

\subsection{Spinneret Gauge}

Two different spinneret gauges were used to fabricate the PP fibers under the same conditions of $230{ }^{\circ} \mathrm{C}, 14,000 \mathrm{rpm}$, and a working distance of $14 \mathrm{~cm}$. The two gauges were $30-\mathrm{G}$ and $20-\mathrm{G}$ with $0.16-$ and $0.60-\mathrm{mm}$ inner diameter orifices, respectively. The $30-\mathrm{G}$ spinneret produced fibers with smaller diameters, $2.27 \pm 0.99 \mu \mathrm{m}$ versus $5.39 \pm 2.08 \mu \mathrm{m}$. The fibers yielded when using the 30-G spinneret also were more uniform. Previous research observed these same trends when forming polyacrylonitrile fibers by centrifugal spinning. ${ }^{5}$ The $30-G$ spinneret was used for the remainder of this study because it produced more desirable fibers than the $20-\mathrm{G}$ spinneret.

\subsection{Rotational Speed}

The effect of the spinneret rotational speed on fiber formation and morphology was examined at rotational speeds between 6,000 and 18,000 rpm. Other conditions were fixed: heating temperature at $230{ }^{\circ} \mathrm{C}$ and a working distance of $14 \mathrm{~cm}$. Figure 1 displays selected images of fibers formed at various rotation speeds and their resulting fiber diameter distributions. Faster rotational speeds yielded smaller fiber diameters (Table 1 and Fig. 2). At slower rotational speeds $(6,000 \mathrm{rpm})$ not only were larger fiber diameters observed, but also large diameter distributions. Increasing the rotational speed to $10,000 \mathrm{rpm}$ improved the fiber diameter and uniformity. Raising the rotational speed beyond 10,000 rpm yielded insignificant improvements. 

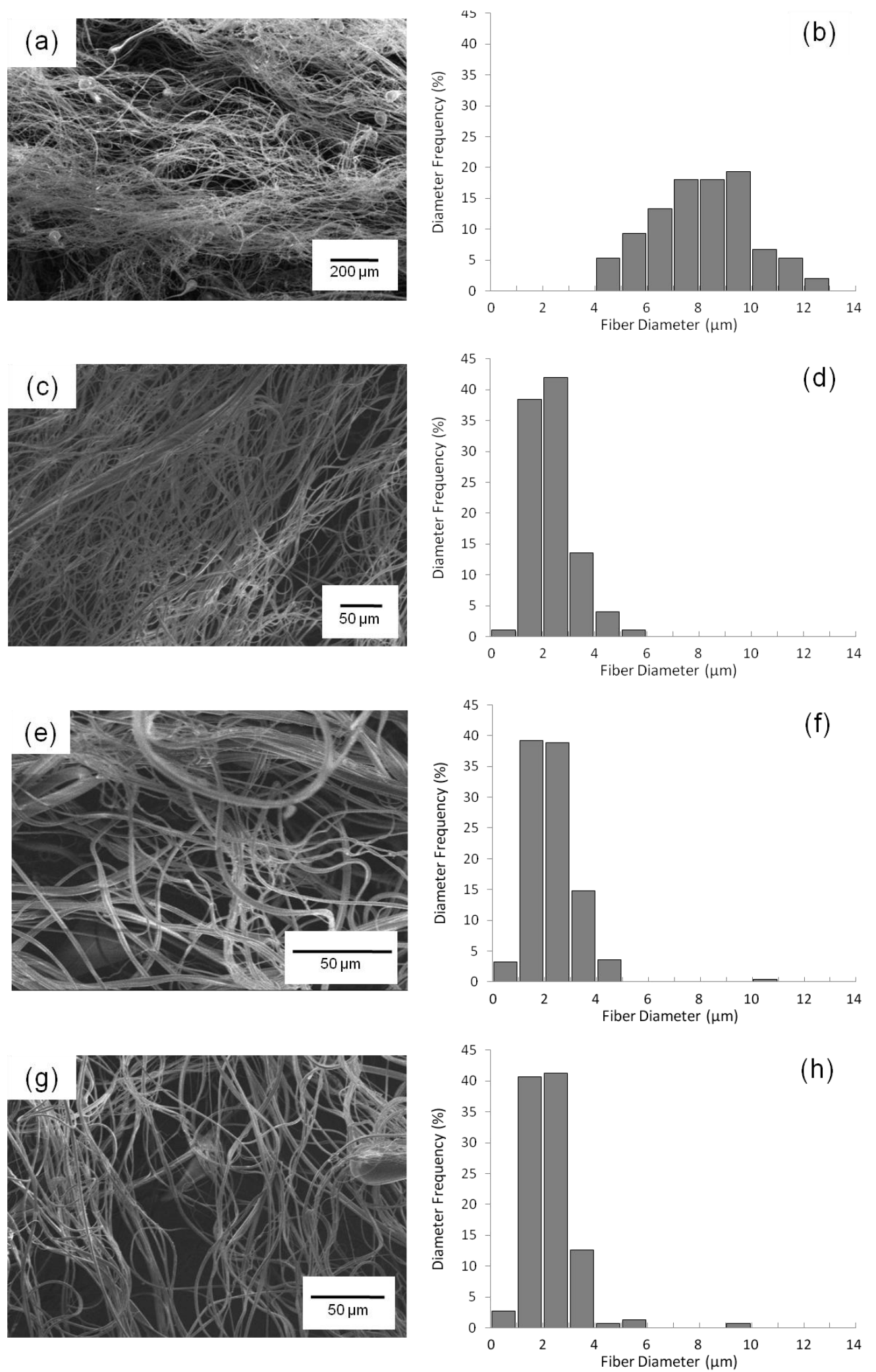

Fig. 1 SEM images paired with fiber diameter distributions of PP microfibers melt spun with a 30-G spinneret at $230{ }^{\circ} \mathrm{C}$ and a collector distance of $14 \mathrm{~cm}$ with varying rotational speeds. a/b) 6,000 rpm, c/d) 10,000 rpm, e/f) 14,000 rpm, and g/h) 18,000 rpm 
Table 1 Fiber diameter of melt-spun polypropylene fibers at varying rotational speeds

\begin{tabular}{|c|c|}
\hline $\begin{array}{c}\text { Rotational Speed } \\
(\mathbf{r p m})\end{array}$ & $\begin{array}{c}\text { Fiber Diameter } \\
(\boldsymbol{\mu m})\end{array}$ \\
\hline 6,000 & $8.28 \pm 2.18$ \\
\hline 10,000 & $2.35 \pm 0.81$ \\
\hline 14,000 & $2.27 \pm 0.99$ \\
\hline 18,000 & $2.25 \pm 1.01$ \\
\hline
\end{tabular}

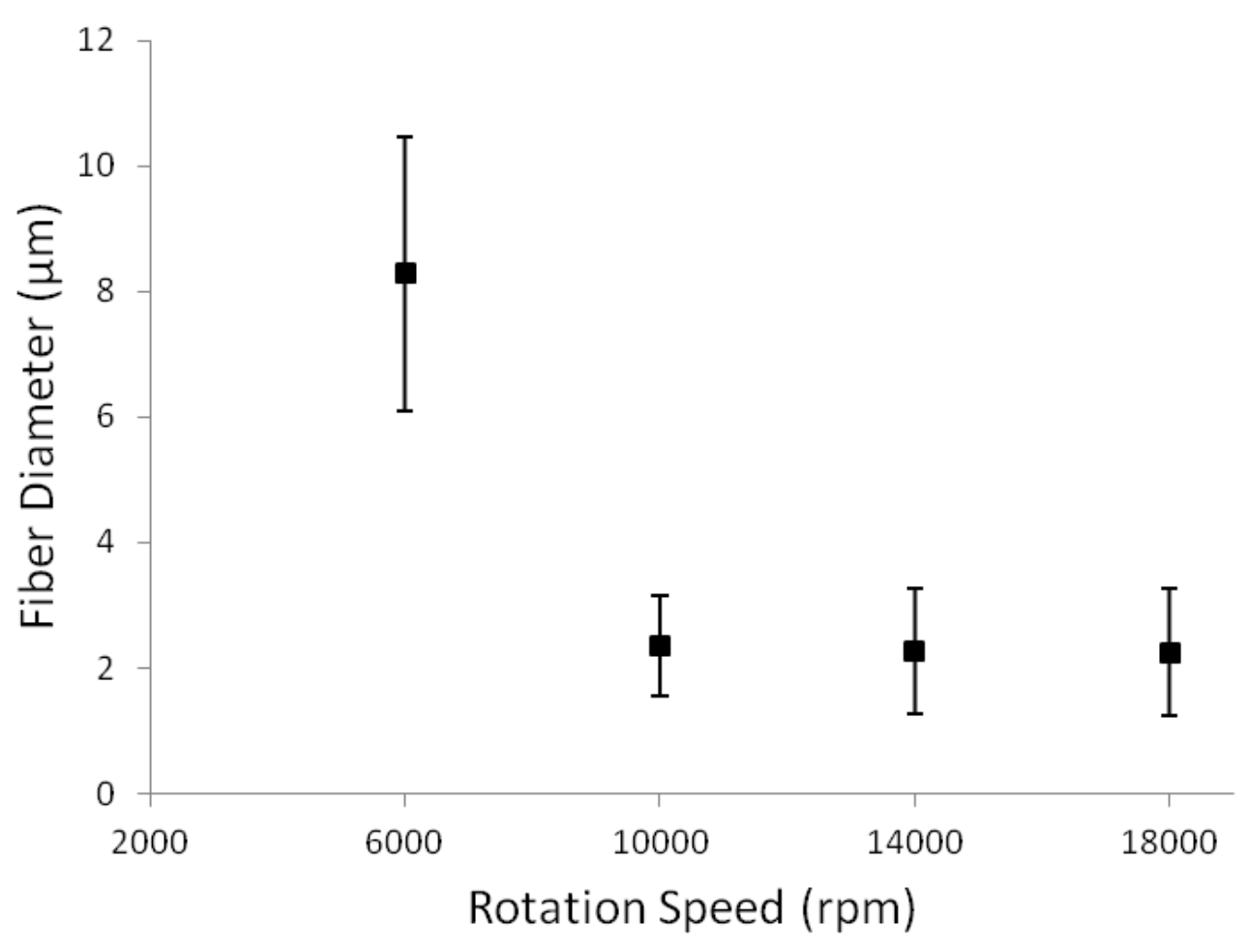

Fig. 2 Melt spun polypropylene fiber diameters prepared at $230{ }^{\circ} \mathrm{C}$ and at a working distance of $14 \mathrm{~cm}$

\subsection{Temperature}

The temperature of the polymer during fiber formation between 200 and $250{ }^{\circ} \mathrm{C}$ did not significantly impact fiber diameter (see Table 2). Significant differences in morphology were observed in the SEM micrographs at these temperatures (see Fig. 3). Although the melting temperature of polypropylene is roughly $150{ }^{\circ} \mathrm{C}$, the lowest temperature selected in this study was $200{ }^{\circ} \mathrm{C}$ to decrease the viscosity of the polymer to a degree that allowed the polymer to flow freely through the spinneret orifices. At operating temperatures close to the melting temperature, few fibers were produced. Between 200 and $250{ }^{\circ} \mathrm{C}$, the fiber diameter distributions were fairly similar. But fibers produced at $250{ }^{\circ} \mathrm{C}$ had beads as well as evidence of polymer decomposition. This beading may be a result of the polymer having too low of a viscosity under these conditions. 
Table 2 Fiber diameter averages and standard deviations at different operating temperatures

\begin{tabular}{|c|c|}
\hline $\begin{array}{c}\text { Temperature } \\
\left({ }^{\circ} \mathbf{C}\right)\end{array}$ & $\begin{array}{c}\text { Fiber Diameter } \\
(\boldsymbol{\mu m})\end{array}$ \\
\hline 200 & $1.91 \pm 0.86$ \\
\hline 230 & $2.27 \pm 0.99$ \\
\hline 250 & $2.39 \pm 0.85$ \\
\hline
\end{tabular}

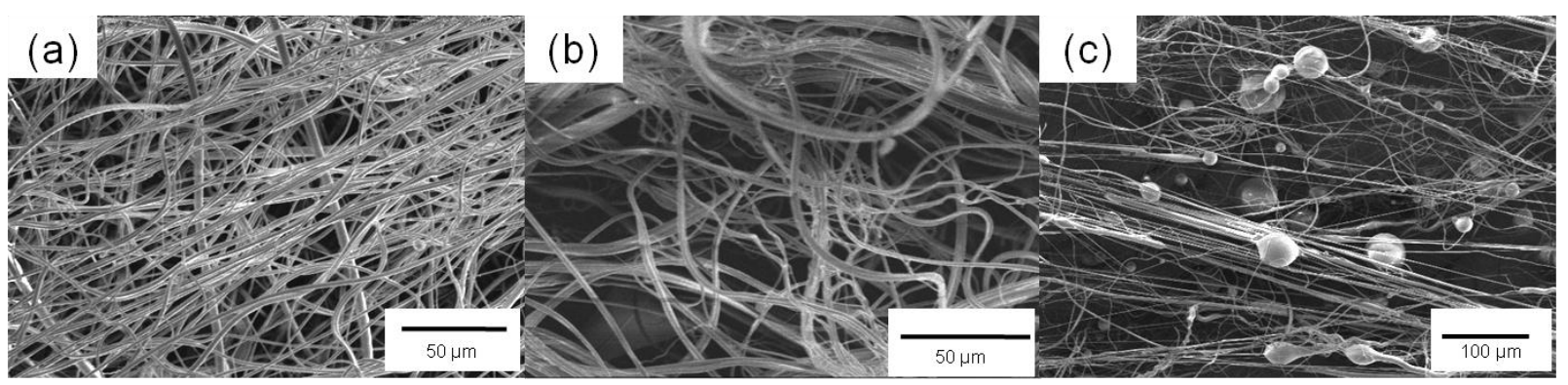

Fig. 3 SEM micrographs of polypropylene fibers produced at 14,000 rpm, with a working distance of $14 \mathrm{~cm}$ at varying temperatures: a) $200{ }^{\circ} \mathrm{C}$, b) $230{ }^{\circ} \mathrm{C}$, and c) $250{ }^{\circ} \mathrm{C}$

\subsection{Working Distance}

The orifice to collector distance impacted the average fiber diameter by a small amount, with statistically smaller fibers formed for longer working distances. A more appreciable difference in the fibers formed at different working distances can be seen in the fiber uniformity and morphology. At a working distance of 10 and $12 \mathrm{~cm}$, some fiber beading was present (Fig. 4). Fibers formed at these working distances also had higher standard deviations and therefore smaller normalized distribution peak heights (see Table 3 and Fig. 5). Fibers formed at a working distance of $14 \mathrm{~cm}$ were the most uniform and absent of beading.

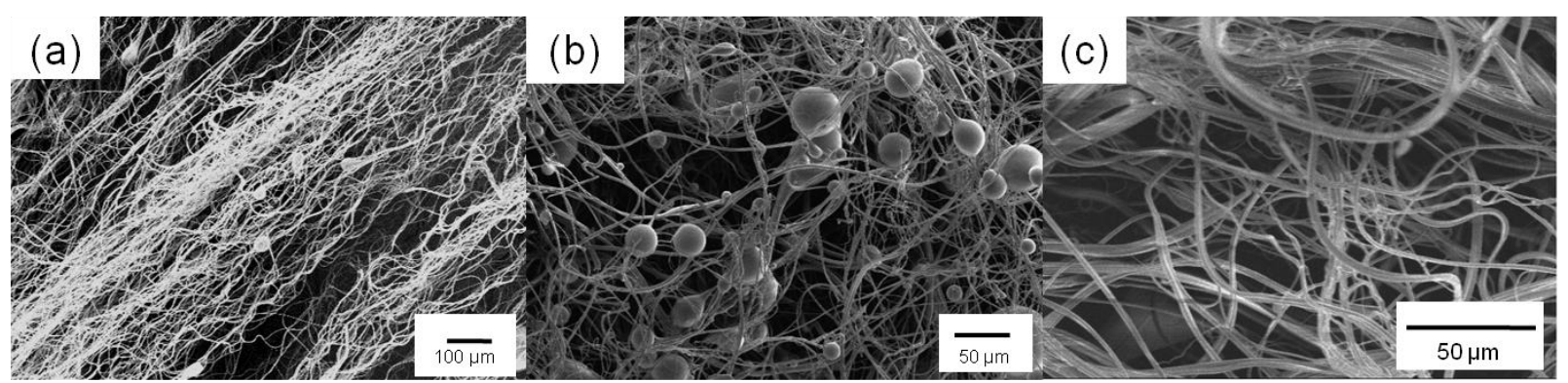

Fig. 4 SEM images of polypropylene fibers produced at $230{ }^{\circ} \mathrm{C}, 14,000 \mathrm{rpm}$, and varying spinneret-collector distances: a) $10 \mathrm{~cm}$, b) $12 \mathrm{~cm}$, and c) $14 \mathrm{~cm}$ 
Table 3 Fiber diameter averages and standard deviations with distribution peak heights at different working distances.

\begin{tabular}{|c|c|c|}
\hline $\begin{array}{c}\text { Working Distance } \\
(\mathbf{c m})\end{array}$ & $\begin{array}{c}\text { Fiber Diameter } \\
(\boldsymbol{\mu m})\end{array}$ & Normalized Distribution Peak Height \\
\hline 10 & $3.59 \pm 1.41$ & 0.283 \\
\hline 12 & $3.00 \pm 1.44$ & 0.276 \\
\hline 14 & $2.27 \pm 0.99$ & 0.401 \\
\hline
\end{tabular}

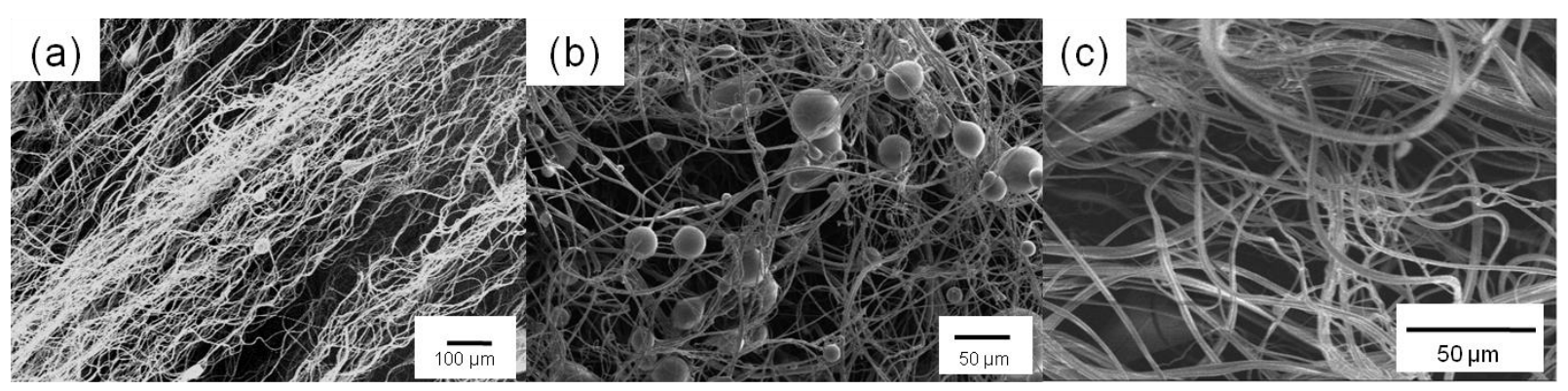

Fig. 5 SEM images of polypropylene fibers produced at $230{ }^{\circ} \mathrm{C}, 14,000 \mathrm{rpm}$, and varying spinneret-collector distance. a) $10 \mathrm{~cm}$, b) $12 \mathrm{~cm}$, and c) $14 \mathrm{~cm}$

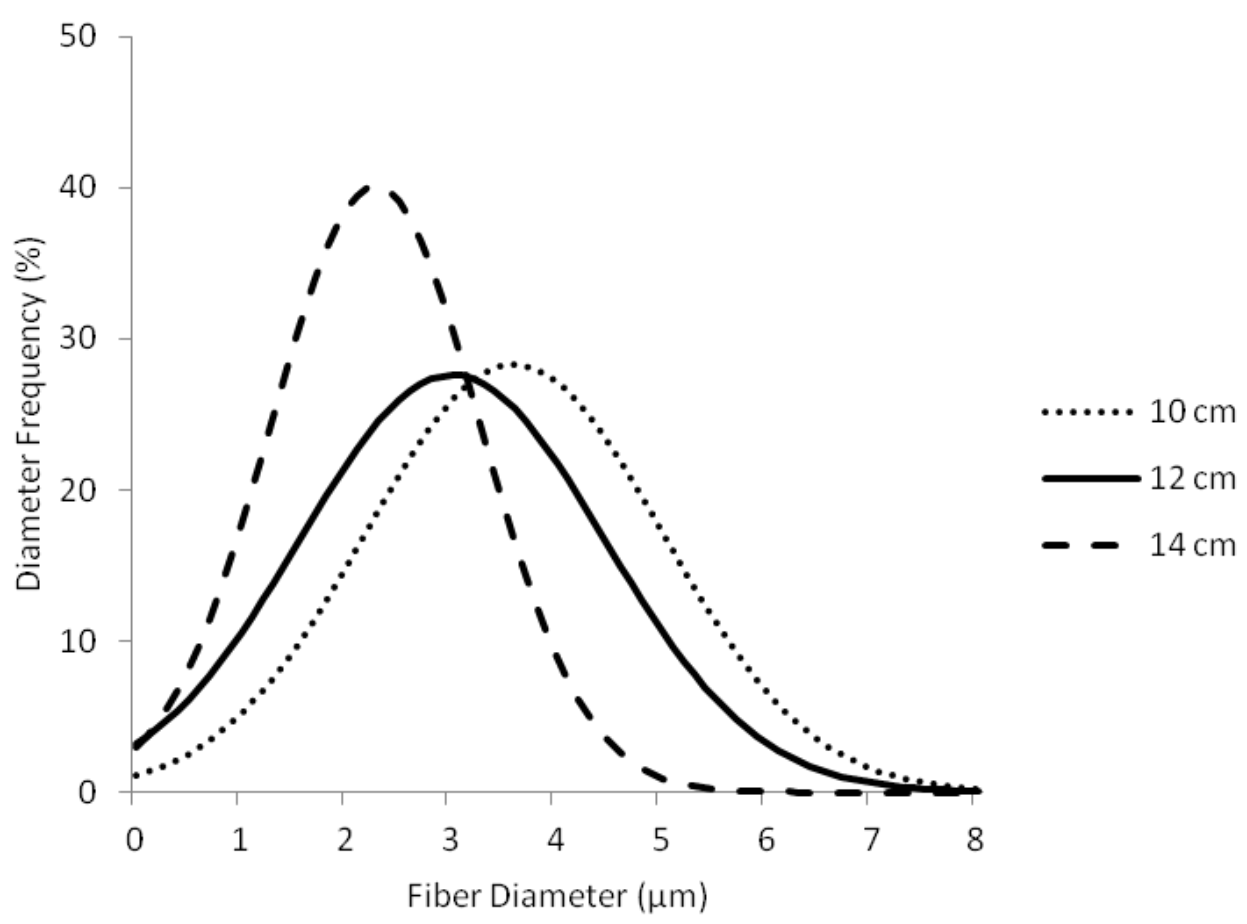

Fig. 6 Normalized distributions of fiber diameters produced at $230{ }^{\circ} \mathrm{C}$, $14,000 \mathrm{rpm}$, and varying spinneret-collector distances 


\section{Conclusions}

Many applications of nanofibers depend on the fiber diameters to be as small as possible because of the properties obtained from features such as high surface area to volume ratios. When fabricating polypropylene fibers via centrifugal spinning, certain operating parameters had significant effects on the average fiber diameters and morphology. The 30-G spinneret produced smaller and more uniform fibers. Increasing rotational speeds of the spinneret up to $10,000 \mathrm{rpm}$ yielded uniform and relatively small fiber diameters. Increasing spinneret rotational speeds beyond 10,000 rpm was not justified by the small improvements in fiber diameter observed. Operating temperatures close to the melting point of polypropylene $\left(<200{ }^{\circ} \mathrm{C}\right)$ reduced the total fiber yield significantly and high temperatures $\left(>230^{\circ} \mathrm{C}\right)$ resulted in fiber beading along with decomposition and burning of the fibers produced. A working distance of $14 \mathrm{~cm}$ was found to be optimal in reducing the polypropylene fiber diameters while increasing fiber uniformity. 


\section{References}

1. Wang L, Yu Y, Chen PC, Zhang DW, Chen $\mathrm{CH}$. Electrospinning synthesis of $\mathrm{C} / \mathrm{Fe} 3 \mathrm{O} 4$ composite nanofibers and their application for high performance lithium-ion batteries. J Power Sources. 2008;83:717-723.

2. Zhang Q, Welch J, Park H, Wu CY, Sigmund W, Marijnissen JCM. Improvement in nanofiber filtration by multiple thin layers of nanofiber mats. J Aerosol Sci. 2010;41: 230-236.

3. Sill TJ, von Recum HA. Electro spinning: applications in drug delivery and tissue engineering. Biomaterials. 2008;29:1989-2006.

4. Sarkar K, Gomez C, Zambrano S, Ramirez M, Hoyos, E, Vasquez H, Lozano, K. Electrospinning to Forcespinning. Mater Today. 2010;13:12-14.

5. Lu Y, Li Y, Zhang S, Xu G, Fu K, Lee H, Zhang X. Parameter study and characterization for polyacrylonitrile nanofibers fabricated via centrifugal spinning process. Eur Polym J. 2013;49:3834-3845. 


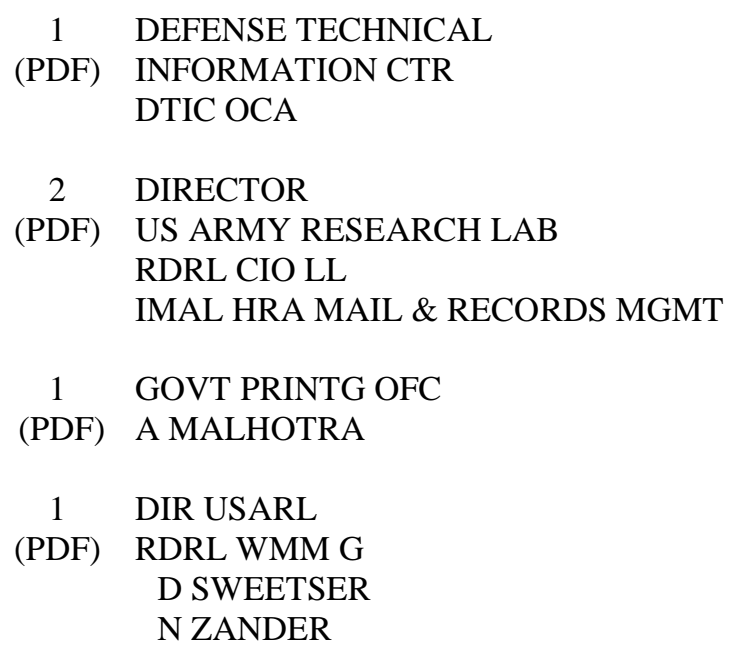


INTENTIONALLY LEFT BLANK. 